\title{
CONTROLE DE Spodoptera frugiperda (J. E. SMITH, 1797) NA CULTURA DO MILHO COM INSETICIDAS DE DIFERENTES GRUPOS QUÍMICOS
}

Dalcimar Regina Batista Wangen ${ }^{\text {; }}$ Paulo Homero Soares Pereira Júnior²; Willyam dos Santos Santana ${ }^{2}$

1. Professora Doutora do Instituto Federal Goiano, Campus Urutaí, Urutaí, GO,

Brasil. E-mail: dbwangen@gmail.com

2.Engenheiros Agrônomos autônomos.

Recebido em: 08/09/2015 - Aprovado em: 14/11/2015 - Publicado em: 01/12/2015

DOI: http://dx.doi.org/10.18677/Enciclopedia_Biosfera_2015_119

\section{RESUMO}

A lagarta-do-cartucho, Spodoptera frugiperda (J. E. Smith, 1797) é a principal praga da cultura do milho (Zea mays L.), capaz de reduzir entre 17,7 a 55,6\% o rendimento de grãos. Seu controle tem sido realizado essencialmente com inseticidas, cujo grupo químico nem sempre é seletivo aos agentes de controle biológico, além do elevado número de aplicações, em alguns casos, de 10 a 14. Objetivou-se estudar o efeito de inseticidas de diferentes grupos químicos e mecanismos de ação sobre a população de lagarta-do-cartucho na cultura do milho, a fim de sugerir alternativa de controle químico desta praga mais segura ao meio ambiente. O experimento foi conduzido na Fazenda Experimental da Fundação Carmelitana Mário Palmério, em Monte Carmelo, MG. O delineamento experimental foi de blocos ao acaso, com cinco tratamentos, com quatro repetições. Os tratamentos consistiram de uma aplicação dos inseticidas lambda-cialorina + chlorantranilipole, Metoxifenozida, Cipermetrina, Clorpirifós, e uma testemunha (sem inseticida). Foram feitas amostragens do número de lagartas vivas nas plantas de milho antes da aplicação dos inseticidas e até o $35^{\circ}$ dia após a aplicação, com intervalo de sete dias entre cada avaliação. Os dados foram submetidos à análise de variância e, quando do teste $\mathrm{F}$ significativo, as médias foram comparadas entre si pelo teste de Tukey a 0,05 de significância. Os inseticidas Lambda-cialotrina + Chlorantraniliprole, Metoxifenozida e Cipermetrina reduziram o número de lagartas vivas em relação à testemunha em pelo menos uma avaliação. No entanto, nenhum destes produtos alcançou eficiência mínima de controle de $80 \%$, em nenhuma das avaliações.

PALAVRAS-CHAVE: lagarta-do-cartucho, Lambda-cialotrina + Chlorantraniliprole, Metoxifenozida e Cipermetrina. Zea mays L.,

\section{CONTROL OF Spodoptera frugiperda (J. E. Smith, 1797) IN MAIZE WITH DIFFERENT GROUPS OF INSECTICIDES}

\author{
ABSTRACT \\ The caterpillar of the cartridge, Spodoptera frugiperda (J. E. Smith, 1797) is the main \\ pest of maize (Zea mays L.), capable of reducing grain yield between 17.7 to $55.6 \%$. \\ Its control has been accomplished primarily with the use of insecticides, whose
}


chemical group is not always selective to biological control agents, in addition to the high number of applications, in some cases, 10 to 14. The objective of this study was to evaluate the effect of insecticides from different chemical groups and mechanisms of action on the population of Spodoptera frugiperda in maize in order to suggest an environmentally safer alternative for chemical control of this pest. The experiment was conducted at the Experimental Farm of Fundação Carmelitana Mário Palmério, in Monte Carmelo, MG, Brazil. The experimental design was in randomized blocks, with five treatments, with four replications. The treatments consisted of an application of the insecticides lambda-cialorina + chlorantranilipole, Methoxyfenozide, cypermethrin, Chlorpyrifos, and a control (without insecticide). The number of live caterpillars were sampled in maize plants before application of the pesticides and even the 35th after application, with an interval of seven days between each assessment. The data were submitted to variance analysis and when the significant $\mathrm{F}$ test, the averages were compared by Tukey test at 0.05 significance. The Lambdacyhalothrin insecticide + Chlorantraniliprole, Methoxyfenozide Cypermethrin and reduced the number of live caterpillars compared to control on at least one evaluation. However, none of these products has reached a minimum efficiency of $80 \%$ control.

KEYWORDS: Fall armyworm, Zea mays, Lambda-cialotrina + Chlorantraniliprole, Metoxifenozida e Cipermetrina.

\section{INTRODUÇÃO}

O plantio sucessivo da cultura do milho tem promovido a formação de uma verdadeira ponte biológica para a lagarta-do-cartucho, Spodoptera frugiperda (J.E. Smith, 1797) (Lepidoptera: Noctuidae) (OTA et al., 2011), considerada a principal praga da cultura do milho, por sua ocorrência generalizada e por atacar todos os estágios desenvolvimento da planta (CRUZ, 2008).

As lagartas iniciam a alimentação raspando os tecidos verdes de um lado da folha, deixando intacta a epiderme membranosa do lado oposto. Lagartas maiores, em geral, dirigem-se para o interior do cartucho onde fazem buracos na folha, podendo destruir completamente pequenas plantas ou causar severos danos em plantas maiores (CAMPANHA et al., 2012). As larvas também penetram no colmo através do cartucho, causando o sintoma conhecido como "coração morto", devido a danos ao ponto de crescimento da planta. Quando atacam as espigas, ocasionam má formação ou mesmo impedem a formação de grãos. O ataque deste inseto também pode levar a danos diretos às plantas, através de sua penetração nos tecidos, onde deixam orifícios que se constituem porta de entrada para fungos e bactérias, agentes estes causadores de várias doenças, diminuindo o potencial de produção e a qualidade dos grãos (LOPES, 2010). De acordo com CRUZ (2008), a redução nos rendimentos de grãos devido ao ataque desta praga varia de 17,7 a $55,6 \%$, de acordo com o estágio de desenvolvimento e dos genótipos de milho.

O controle da lagarta-do-cartucho tem sido realizado essencialmente com inseticidas químicos, cuja escolha nem sempre leva em consideração o grau de seletividade aos agentes de controle biológico. Em alguns casos, são realizadas de 10 a 14 aplicações na cultura do milho no Brasil (VALICENTE \& TUELHER, 2009).

O uso de produtos químicos de amplo espectro de ação para o controle de pragas provoca três fenômenos ecológicos: ressurgência da praga alvo, surtos de pragas secundárias e desenvolvimento de resistência aos inseticidas. Todos esses 
fenômenos estão diretamente relacionados com a perturbação do controle natural em função da "dependência" do inseticida, da qual é difícil se livrar. É um problema global em extensão e tem contribuído para aumentar os problemas econômicos e ecológicos, despertando o interesse de pesquisadores e empresas em lançar no mercado produtos seletivos aos inimigos naturais das pragas (CRUZ, 1995).

Os inseticidas existentes no mercado podem ser seletivos de diferentes modos. O primeiro deles ocorre quando o produto alcança um determinado inseto benéfico, mas há baixa absorção do inseticida pelo tegumento do mesmo. Isso pode ocorrer, por exemplo, no caso das tesourinhas predadoras (Doru luteipes) da lagarta-do-cartucho. Alguns inseticidas, como os piretróides, não atingem os insetos adultos de tesourinhas, simplesmente porque seu tegumento duro impede a entrada do produto. $O$ sistema enzimático de alguns insetos também pode produzir enzimas que degradam a substância tóxica ingerida por estes. A seletividade também pode ser obtida pelo modo apropriado e favorável de se aplicar o inseticida, como por exemplo, inseticida sistêmico aplicado no solo que circula na seiva da planta e atinge apenas as pragas sugadoras (cigarrinhas, pulgões, etc.), mas não os inimigos naturais. Atualmente existem diversos inseticidas seletivos no mercado, dentre os quais destacam-se os inseticidas reguladores de crescimento que retardam, aceleram ou impedem a ecdise (troca de pele dos insetos), bem como aqueles que interferem na deposição da quitina na cutícula do inseto, sendo bastante seletivos por atuarem somente nas formas jovens dos insetos-praga (MARUCCI, 2003).

Este trabalho teve como objetivo estudar o efeito de uma única aplicação de inseticidas de diferentes grupos químicos e mecanismos de ação sobre a população de lagarta-do-cartucho na cultura do milho, a fim de sugerir alternativa de controle químico desta praga mais segura ao meio ambiente.

\section{MATERIAL E MÉTODOS}

O experimento foi conduzido na Fazenda Experimental da Fundação Carmelitana Mário Palmério (FUCAMP), localizada no município de Monte Carmelo

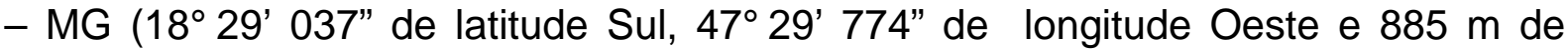
altitude), no período de maio a julho de 2013.

O delineamento experimental foi de blocos ao acaso, com cinco tratamentos (Tabela 1), com quatro repetições. A unidade experimental foi constituída de cinco fileiras de cinco metros de comprimento, espaçadas entre si $0,80 \mathrm{~m}$ (totalizando 20 $\mathrm{m}^{2}$ ), com seis plantas por metro linear (população de 75.000 plantas por hectare). Tomou-se como área útil da parcela as três fileiras centrais, desprezando-se um metro nas extremidades das linhas (totalizando $7,2 \mathrm{~m}^{2}$ ).

O solo da área foi preparado de forma convencional, por meio de uma aração com arado de discos seguida de uma gradagem com grade niveladora. Foram empregadas sementes de milho híbrido (AG 1051). A adubação e demais tratos culturais foram feitos conforme CRUZ et al. (2008).

Os inseticidas foram aplicados aos 45 dias após a emergência das plântulas, quando as mesmas já se apresentavam infestadas com lagartas-do-cartucho. Empregou-se volume de calda de $300 \mathrm{~L} \mathrm{ha}^{-1}$, sem uso de adjuvantes, aplicados com auxílio de pulverizador costal, à pressão constante, com ponta tipo leque, com o jato dirigido para o interior do cartucho foliar.

Foram feitas amostragens do número de lagartas vivas nas plantas de milho antes da aplicação dos inseticidas e até o $35^{\circ}$ após a aplicação, com intervalo de sete dias entre cada avaliação. Para tanto, tomaram-se ao acaso dez plantas na 
área útil de cada unidade experimental, as quais foram arrancadas e submetidas a contagem do número de lagartas vivas na parte aérea das mesmas.

TABELA 1. Tratamentos empregados no controle de Spodoptera frugiperda na cultura do milho, Monte Carmelo - MG, 2013.

\begin{tabular}{|c|c|c|c|c|c|}
\hline Tratamentos & Grupo químico & Ingrediente ativo & $\begin{array}{l}\text { Concentração } \\
\text { e formulação }{ }^{1}\end{array}$ & $\begin{array}{c}\text { Classe } \\
\text { toxicológica }\end{array}$ & g i.a. ha ${ }^{-1}$ \\
\hline T1 & Testemunha & - & - & - & - \\
\hline T2 & $\begin{array}{c}\text { Piretrlóide + } \\
\text { Antranilamida }\end{array}$ & $\begin{array}{c}\text { lambda-cialorina + } \\
\text { chlorantranilipole }\end{array}$ & $\begin{array}{l}50 \mathrm{SC} \\
100 \mathrm{SC}\end{array}$ & II & $\begin{array}{c}7,5 \\
15,0\end{array}$ \\
\hline T3 & Hidrazida & Metoxifenozida & 240 SC & III & 43,2 \\
\hline $\mathrm{T} 4$ & Piretrlóide & Cipermetrina & $250 \mathrm{EC}$ & 1 & 16,25 \\
\hline T5 & Organofosforado & Clorpirifós & $480 \mathrm{EC}$ & I & 288,0 \\
\hline
\end{tabular}

II - Extremamente tóxico, II - Altamente tóxico, III - Medianamente tóxico.

${ }^{2}$ SC: Suspensão concentrada, EC: Concentrado emulsionável.

Para cálculo da porcentagem de eficiência dos inseticidas (\%E) empregou-se a equação de Henderson e Tilton (1952):

$$
E F(\%)=100 \times \frac{(1-N 1 \times N 2)}{N 3 \times N 4}
$$

Em que:

$E F(\%)$ : porcentagem de eficiência

N1: Número de insetos na testemunha antes da aplicação

N2: Número de insetos no tratamento após a aplicação

N3: Número de insetos na testemunha após a aplicação

N4: Número de insetos no tratamento antes da aplicação

Os dados foram submetidos a análise de variância e quando do teste $F$ significativo, as médias foram comparadas entre si pelo teste de Tukey a 0,05 de significância, tendo-se empregado para tanto o Programa Estatístico Sisvar (FERREIRA, 2000).

\section{RESULTADOS E DISCUSSÃO}

Houve diferença significativa $(P<0,05)$ entre os tratamentos para o número de lagartas vivas somente aos 7, 21 e 28 dias após a aplicação dos inseticidas (Tabela 2). Aos 7 DAA, somente os inseticidas lambda-cialorina + chlorantranilipole e metoxifenozida reduziram significativamente o número de lagartas vivas (Tabela 2), com eficiência de $78 \%$ e $32 \%$, respectivamente (Tabela 3).

Embora aos 14 DAA o inseticida cipermetrina tenha apresentado eficiência de $68 \%$ no controle da lagarta-do-cartucho (Tabela 3), seu efeito não diferiu significativamente dos demais produtos, no que concerne ao número de lagartas vivas (Tabela 2 ). 
TABELA 2. Número de lagartas vivas após a aplicação de inseticidas químicos durante 35 dias de avaliação. Monte Carmelo MG, 2013.

\begin{tabular}{|c|c|c|c|c|c|}
\hline \multirow[t]{2}{*}{ Tratamentos } & \multicolumn{5}{|c|}{ Número de lagartas vivas } \\
\hline & 7 DAA & 14 DAA & $21 \mathrm{DAA}$ & $28 \mathrm{DAA}$ & 35 DAA \\
\hline \multirow{5}{*}{$\begin{array}{l}\text { Testemunha } \\
\text { Lambda-cialotrina + } \\
\text { Chlorantraniliprole } \\
\text { Metoxifenozida } \\
\text { Cipermetrina } \\
\text { Clorpirifós } \\
\end{array}$} & $1,8 \mathrm{a}$ & $1,0 \mathrm{a}$ & $1,2 \mathrm{a}$ & $1,6 \mathrm{a}$ & $1,2 \mathrm{a}$ \\
\hline & $0,2 \mathrm{c}$ & $0,8 \mathrm{a}$ & $0,4 a b$ & $0,0 \mathrm{~b}$ & $0,4 a$ \\
\hline & $0,2 \mathrm{c}$ & $0,4 \mathrm{a}$ & $0,0 \mathrm{~b}$ & $0,0 \mathrm{~b}$ & $0,2 \mathrm{a}$ \\
\hline & $1,4 \mathrm{ab}$ & $0,2 \mathrm{a}$ & $0,2 a b$ & $0,4 \mathrm{~b}$ & $1,0 \mathrm{a}$ \\
\hline & $0,4 \mathrm{ab}$ & $0,6 \mathrm{a}$ & $0,8 a b$ & $0,8 a b$ & $0,2 \mathrm{a}$ \\
\hline C.V. (\%) & 73 & 139 & 118 & 107 & 115 \\
\hline \multicolumn{6}{|c|}{$\begin{array}{l}\text { 1Dias antes da aplicação dos inseticidas; }{ }^{2} \text { Dias após a aplicação dos inseticidas; } \\
{ }^{3} \text { Médias seguidas pela mesma letra na coluna não diferem entre si pelo teste de } \\
\text { Tukey a 0,05\% de significância. }\end{array}$} \\
\hline \multicolumn{6}{|c|}{$\begin{array}{l}\text { TABELA 3. Eficiência dos inseticidas químicos durante } 35 \text { dias após a } \\
\text { aplicação dos inseticidas (DAA), calculada segundo } \\
\text { Henderson \& Tilton (1952). Monte Carmelo - MG, 2013. }\end{array}$} \\
\hline \multirow[t]{2}{*}{ Tratamentos } & \multicolumn{5}{|c|}{ Número de lagartas vivas } \\
\hline & 7 DAA & $14 \mathrm{DAA}$ & 21 DAA & 28 DAA & 35 DAA \\
\hline Testemunha & 78 & & 37 & 63 & 36 \\
\hline $\begin{array}{l}\text { Lambda-cialotrina + } \\
\text { Chlorantraniliprole }\end{array}$ & 32 & 30 & 69 & 42 & 47 \\
\hline Metoxifenozida & - & 68 & 57 & 18 & - \\
\hline Cipermetrina & 14 & - & - & 1,0 & 40 \\
\hline Clorpirifós & & & - & - & \\
\hline
\end{tabular}

Aos 28 DAA, o inseticida clorpirifós foi o que apresentou o pior desempenho (Tabela 2), com eficiência de apenas $1 \%$, enquanto lambda-cialorina + chlorantranilipole evidenciou eficiência de 63\% (Tabela 3). De modo geral, o inseticida metoxifenozida foi o que apresentou o melhor desempenho, tendo reduzido significativamente a população da lagarta-do-cartucho aos 7, 21 e 28 DAA (Tabela 2), seguido do lambda-cialotrina + Chlorantranilipole, cujo efeito foi significativo aos 7 e 28 DAA.

A eficiência dos inseticidas estudados ficou abaixo do mínimo recomendado pela Ministério da Agricultura, Pecuária e Abastecimento (REUNIÃO DA COMISSÃO SUL-BRASILEIRA DE PESQUISA DE TRIGO, 2004), em todas as avaliações (Tabela 3), uma vez que, de acordo com esse órgão, em condições de campo, a eficiência mínima recomendada deve ser de $80 \%$ para insetos-praga da parte aérea. Lambda-cialotrina + chlorantraniliprole foi o que chegou mais próximo da eficiência mínima, apenas 7 DAA, com $78 \%$ de eficiência. Nas demais avaliações, sua eficiência ficou entre 37 e $63 \%$. Os inseticidas metoxifenozida, cipermetrina e clorpirifós apresentaram eficiência máxima de 69 (30-69\%), 68 (18-68\%) e 40\% (1$40 \%)$, respectivamente.

BELLETTINI et al. (2011), ao avaliarem o efeito de lambda-cialotrina + chlorantraniliprole na dose de $5+10 \mathrm{~g}$ i. a. ha ${ }^{-1}$, respectivamente, no controle da lagarta-do-cartucho na cultura do algodão verificaram queda significativa na população desta praga, comparado ao tratamento testemunha, com eficiência 
superior a $80 \%$ até 10 DAA. A melhor eficiência desse tratamento no algodão, embora em dose inferior, comparada àquela empregada no presente estudo na cultura do milho, pode ser devida a diversos fatores, entre os quais a arquitetura das plantas. De acordo com CRUZ (2008), em plantas de milho mais desenvolvidas, muitas vezes, a eficiência esperada do controle da praga não é alcançada, não pela ineficiência do produto utilizado, mas, sim, devido ao método de aplicação. BUSATO et al. (2005) citam que o fato da lagarta se alojar no interior do cartucho, muitas vezes, dificulta a realização de seu controle por meio de inseticidas sintético.

TOSCANO et al. (2012), ao avaliarem o efeito de clorpirifós não constataram redução da população de lagarta-do-cartucho em milho, com duas aplicações de clorpirifós, em Cassilândia - MS. No entanto, em outro trabalho desenvolvido em Chapadão do Sul - MS, esses mesmos autores, embora também não tenham constatado efeito positivo desse mesmo produto com a primeira aplicação, verificaram redução de $60 \%$ na população dessa praga com uma segunda aplicação. VIANA \& COSTA (1998), por sua vez, constataram eficiência de controle da lagarta-do-cartucho em milho com uma única aplicação da dose $288 \mathrm{~g}$ i. a. ha ${ }^{-1}$ de clorpirifós variando entre 82,9 e 98,7\%, com a dose de, aos 3 DAA.

A baixa eficiência de controle da lagarta-do-cartucho pelos produtos testados no presente estudo pode ser devida, além da dificuldade de contato dos produtos com a lagarta no interior do cartucho, à possível lavagem dos produtos da superfície das folhas pela água de irrigação. VIANA \& COSTA (1998) relataram redução da eficiência de controle de lagarta-do-cartucho em milho devido à chuva após a aplicação dos produtos.

\section{CONCLUSÃO}

Os inseticidas Lambda-cialotrina + Chlorantraniliprole, Metoxifenozida e Cipermetrina reduziram o número de lagartas vivas em relação à testemunha em pelo menos uma avaliação. No entanto, nenhum destes produtos alcançou eficiência mínima de controle de $80 \%$, em nenhuma das avaliações.

\section{AGRADECIMENTOS}

À Fundação Carmelitana Mário Palmério, pelo apoio financeiro necessário à esta pesquisa.

\section{REFERÊNCIAS}

BELLETTINI, S.; BELLETTINI, N. M. T.; NISHIMURA, M.; BELLETTINI, R.; FONTES, T. B.; FONTES NETO, D. T.; CARVALHO, F. K. Controle da Spodoptera frugiperda (J. E. Smith, 1797) com inseticidas no algodoeiro. In: CONGRESSO BRASILEIRO DE ALGODÃO, 8; COTTON EXPO, 1.; São Paulo. Evolução da cadeia para construção de um setor forte: Anais... Campina Grande, PB: Embrapa Algodão, 2011. p. 123-127 (CD-ROM).

BUSATO, G. R.; GRUTZMACHER A. D.; GARCIA M. S.; GIOLO F. P.; ZOTTI M. J; STEFANELLO JUNIOR G. J. Biologia comparada de populações de Spodoptera frugiperda (J.E. Smith) (Lepidoptera: Noctuidae) em folhas de milho e arroz. Neotropical Entomology, Londrina, v. 34, n. 5, p. 743-750, 2005. 
CAMPANHA, M. M.; CRUZ, J. C.; RESENDE, A. V.; COELHO, A. M.; KARAM, D.; SILVA, G. H. da; PEREIRA FILHO, I. A.; CRUZ, I.; MARRIEL, I. E.; GARCIA, J. C.; QUEIROZ, L. R.; PIMENTEL, M. A. G.; GONTIJO NETO, M. M.; VIANA, P. A.; ALBUQUERQUE, P. E. P de; COSTA, R. V. da; MENDES, S. M.; QUEIROZ, V. A. Sistema de produção integrada de milho para Região Central de Minas Gerais. Sete Lagoas: Embrapa Milho e Sorgo, 2012. 74 p. (Documentos: Embrapa Milho e Sorgo).

CRUZ, I. A lagarta-do-cartucho na cultura do milho. Sete Lagoas: EMBRAPACNPMS, 1995. 45 p. (Circular Técnica, 21).

CRUZ, I. Manejo de pragas da cultura do milho. In: CRUZ, J. C.; KARAM, D.; MONTEIRO, M. A. R.; MAGALHÃES, P. C. (Eds.) A cultura do milho. Sete Lagoas: Embrapa Milho e Sorgo, p. 303-362, 2008.

CRUZ, J. C.; KARAM, D.; MONTEIRO, M. A. R.; MAGALHÃES, P. C. (Eds.). A cultura do milho. Sete Lagoas: Embrapa Milho e Sorgo, 2008. 517p.

FERREIRA, D. F. Manual do sistema Sisvar para análises estatísticas. Lavras: UFLA, 2000.

HENDERSON, C. F.; TILTON, E. W. Test with acaricides against the brown wheat mite. Journal of Economic Entomology, Annapolis, v.43, p.157-161, 1952.

LOPES, M. E. O uso do milho Bt no combate à lagarta do cartucho. (2010). Disponível em: <http://rehagro.com.br/plus/modulos/noticias/ler.php?cdnoticia=2067>. Acesso em: 03 de setembro de 2015.

MARUCCI, R. C. A. Seletividade dos inseticidas piretróides. Disponível em: $<$ http://rehagro.com.br/plus/modulos/noticias/ler.php?cdnoticia=86>. Acesso: 27 de janeiro de 2013.

OTA, É. do C.; LOURENÇÃO, A. L.; DUARTE, A. P.; RAMOS JUNIOR, E. U.; ITO, M. A. Desempenho de cultivares de milho em relação à lagarta-do-cartucho. Bragantia, Campinas, v. 70, n. 4, p. 850-859, 2011.

REUNIÃO DA COMISSÃO SUL-BRASILEIRA DE PESQUISA DE TRIGO, 36, 2004, Passo Fundo, RS. Atas e resumos... Reunião da Comissão Sul-brasileira de Pesquisa de Trigo; Seminário Técnico do Trigo - 2004. Organizado por Julio Cesar Barreneche Lhamby - Passo Fundo, RS: Comissão Sul-brasileira de Pesquisa de Trigo, 2004.

TOSCANO, L. C.; CALADO FILHO, G. C.; CARDOSO, A. M.; MARUYAMA, W. I.; TOMQUELSK, G. V. Impacto de inseticidas sobre Spodoptera frugiperda (Lepidoptera, Noctuidae) e seus inimigos naturais em milho safrinha cultivado em Cassilândia e Chapadão do Sul, MS. Arquivos do Instituto Biológico de São Paulo, São Paulo, v. 79, p.223-231, 2012. 
VALICENTE. F. H.; TUELHER, E. S. Controle biológico da lagarta do cartucho, Spodoptera frugiperda, com Baculovírus. Sete Lagoas: Embrapa Milho e Sorgo, 2009. 14 p. (Circular Técnica, 114).

VIANA, P. A.; COSTA, Ê. F. Controle da lagarta-do-cartucho, Spodoptera frugiperda (J. E. Smith) (Lepidoptera: Noctuidae) na cultura do milho com inseticidas aplicados via irrigação por aspersão. Anais da Sociedade Entomológica do Brasil, Londrina, v. 27, n. 3, p. $451-458,1998$. 